\title{
APLs de Gemas e Joias na Região Metropolitana do Distrito Federal - Possíveis Avanços de Marcas e de Certificações
}

\author{
APL of Gems and Jewels in the Metropolitan Region of DF - Possible \\ Brand Advances and Certifications
}

\author{
Alessandro Aveni ${ }^{1}$ \\ Ângelo Magalhães Júnior ${ }^{1}$ \\ Claudina Maria Costa ${ }^{1}$ \\ Lúcia de Assunção ${ }^{1}$ \\ ${ }^{1}$ Universidade de Brasília, Brasilia, DF, Brasil
}

\begin{abstract}
Resumo
O trabalho tem como objetivo pesquisar os APLs de Gemas e de Joias na Região Metropolitana do Distrito Federal e verificar a possibilidade e o interesse na criação de uma Indicação Geográfica para esse setor. No decorrer da pesquisa, bibliográfica e qualitativa, foi detectado que no DF existia inicialmente um APL de gemas e de joias que foi desativado, permanecendo o APL de Gemas e de Joias da Região Metropolitana do DF em Cristalina (GO). São analisados os destaques e as tendências do mercado de joias no Brasil. A coleta de dados se deu por meio de entrevistas, observação não participante e análise documental. Como resultado preliminar, verificou-se que existem muitos problemas a serem superados, como a questão da organização das associações, da diversificação dos fornecedores pela rapidez de produção e dos acordos sobre concorrência que comprometem a qualidade dos produtos. Foi evidenciada também a falta de incentivos fiscais para o crescimento do setor na Região.
\end{abstract}

Palavras-chaves: Economia Mineral. Indicação Geográfica. Gemas e Joias da Região Metropolitana do DF.

\begin{abstract}
The objective of this work is to investigate the APLs of Gems and Jewelry in the Metropolitan Region of the Federal District and to verify the possibility and interest in the creation of a Geographical Indication for this sector. In the course of the research, bibliographical and qualitative, it was detected that in the DF there was initially an APL of gems and jewels that was deactivated, remaining APL of gems and jewels in the Metropolitan Region of DF, in Cristalina (GO). Data collection was done through interviews, non-participant observation and documentary analysis. As a preliminary result it was found that there are many problems to be overcome, such as the organization of producers, diversification of suppliers by the speed of production and competitiveness that compromises product quality. It was also evidenced the lack of fiscal incentives for the growth of the sector in the Region.
\end{abstract}

Keywords: Mineral Economics. Geographical Indication. Gems and Jewelry from DF Metropolitan Region.

Área Tecnológica: Tecnologia Mineral. 


\section{Introdução}

O Distrito Federal e seu entorno são regiões estratégicas para o desenvolvimento econômico do Brasil devido à sua localização geográfica nas proximidades dos estados de Goiás e Minas Gerais e pelo fato de ter um grupo de designers criativos, abrigar as sedes do Governo Federal, do Distrito Federal e as representações diplomáticas, e de ter, ainda, a mais alta renda per capita do país.

A Região possui um grande potencial a ser explorado no setor de gemas, de joias e de bijuterias, com efetivas possibilidades de desenvolvimento de um Polo de Joias. Uma Indicação Geográfica (IG) para gemas e joias da Região Metropolitana do DF se justifica pelas diversas ações que têm sido realizadas e incentivadas pelo governo do Distrito Federal. O potencial de crescimento assumiu maior dimensão quando a cadeia produtiva de gemas e joias se associou ao setor de turismo, que promove uma forte contribuição na geração de emprego e renda, por não demandar grandes investimentos em infraestrutura e não poluir o meio ambiente.

Lamentavelmente, até hoje, não foi formalizado o pedido de Indicação Geográfica ou a criação de uma marca coletiva que caberia na busca de melhor visibilidade das joias do DF. O objetivo deste artigo é identificar as condições e os gargalos para propor uma certificação de IG ou uma Marca Coletiva no Arranjo Produtivo Local de Gemas e de Joias na Região Metropolitana do DF. Como hipótese de trabalho, se assume a dependência de apoio do governo central, do DF e de agências de desenvolvimento.

Esta pesquisa apresenta um quadro da situação atual para a proposição de uma IG para as gemas e as joias da Região Metropolitana do DF, assim estruturada no referencial teórico: breve histórico das gemas no Brasil, a legislação extração das gemas ou metais preciosos ou Lei do Garimpo e o Novo Marco Regulatório; Gemas e Joias na Região Metropolitana do DF, metodologia de pesquisa, análise e pesquisa de APL de gemas e joias; lapidação e comercialização APL de Gemas e Joias do DF com uma linha do tempo e APL de Cristalina (GO); análise dos elementos para os pedidos de Marca, finalizando com uma conclusão propositiva.

\section{Metodologia}

A pesquisa explora o material bibliográfico disponível sobre o Arranjo Produtivo Local das Joias do Distrito Federal em relação aos dados quantitativos e qualitativos do mercado. Realizou-se o levantamento de informações junto às associações e instituições da cadeia produtiva para verificar as estratégias comerciais e de marcas e as perspectivas para certificações, marcas coletivas e selos de gemas e joias do DF.

A metodologia usada foi a pesquisa bibliográfica e documental de obras e de artigos científicos, realizada na base de dados disponível no repositório de Periódicos da Capes. As palavras-chave foram: gemas e joias; Indicação Geográfica; extração, lapidação e comercialização de gemas na Região Metropolitana do DF. Trata-se de um estudo descritivo, segundo Lakatos e Marconi (2003), com abordagem qualitativa, análise documental e análise da legislação pertinente e com uso de entrevista para identificar as variáveis que influenciam na análise do potencial de Indicação Geográfica de Gemas e Joias na Região Metropolitana do DF. 
A pesquisa de campo se limitou a realizar entrevistas com o gemólogo Wadih Daoud, com Elzivir de Azevedo Guerra e com Tássia de Melo Arraes, ambos analistas em Ciência e Tecnologia, do Grupo de Recursos Minerais (GRMI), do Ministério da Ciência, Tecnologia, Inovações e Comunicações (MCTIC) para validar os resultados da análise bibliográfica.

\section{Resultados e Discussão}

O estudo dos metais preciosos, ou gemas, se concentra na área de Economia Mineral que abrange a aplicação dos princípios, metodologias, instrumentos de análise e avaliação econômica e financeira da indústria de mineração. A economia mineral aborda bens minerais do ponto de vista de recursos nacionais, público e privado. O conceito de economia mineral que recebeu destaque pela excelência foi proposto por David Brooks e publicado nos anais da Convenção de 1967 da American Society for Engineering Education - Mineral Economics as Economics (VALE, 2018).

A importância histórica das gemas remonta ao período colonial do Brasil, quando a mineração teve início com o desbravamento pelas expedições armadas, denominadas Entradas e Bandeira, adentrando o sertão com o objetivo de obter metais preciosos, remover os índios e destruir os quilombos (BOXER, 1969). O Brasil era um fornecedor de pedras preciosas. Foi o maior fornecedor mundial de diamantes durante 150 anos, do início da época colonial até 1866, quando foram descobertos diamantes na África do Sul. Segundo Boxer (1969), foi apenas em 1696 que uma dessas expedições conseguiu encontrar jazidas de ouro nas regiões montanhosas de Minas Gerais e, posteriormente, em Goiás e no Mato Grosso. Diante da diminuição do preço e da qualidade do açúcar, Portugal buscou novas fontes de riquezas no território brasileiro, e logo encontrou nas pedras e metais preciosos o que procurava.

Tornou-se fundamental para Portugal a expansão do ciclo da mineração brasileira por ampliar a riqueza dos portugueses para exportação a outros países. Inicialmente, a exploração das riquezas minerais se concentrava na Região Sudeste e na capital do Brasil, que era Salvador, na Bahia. Depois, a capital foi transferida para o Rio de Janeiro por questões estratégicas de localização, pois tornava mais fácil e rápido o acesso às regiões mineradoras. (SALLES, 1963). O Ciclo de Ouro provocou deslocamentos populacionais de portugueses e brasileiros para novas regiões. A Coroa Portuguesa tinha por objetivo lucrar com toda a atividade gerada por esse ciclo, dessa forma, estabeleceu impostos pesados e determinou que o ouro encontrado tinha que ser controlado pelas Casas de Fundição e transformado em barras para receber o selo da Coroa, que funcionava como uma autorização (Szmrecsányi, 2008).

\subsection{O Marco Regulatório de Mineração}

O Brasil ao longo do tempo desenvolveu uma legislação sobre mineração. A Lei dos Garimpos, Lei n. 11.685, de 2 de junho de 2008, pela Presidência da República Federativa do Brasil, instituiu o Estatuto do Garimpeiro, destinado a disciplinar os seus direitos e deveres.

Nessa Lei, entende-se por: 
I. garimpeiro: toda pessoa física de nacionalidade brasileira que, individualmente ou em forma associativa, atue diretamente no processo da extração de substâncias minerais garimpáveis;

II. garimpo: a localidade onde é desenvolvida a atividade de extração de substâncias minerais garimpáveis, com aproveitamento imediato do jazimento mineral, que, por sua natureza, dimensão, localização e utilização econômica, possam ser lavradas, independentemente de prévios trabalhos de pesquisa, segundo critérios técnicos do Departamento Nacional de Produção Mineral - DNPM; e

III. minerais garimpáveis: ouro, diamante, cassiterita, columbita, tantalita, wolframita, nas formas aluvionar, eluvional e coluvial, scheelita, demais gemas, rutilo, quartzo, berilo, muscovita, espodumênio, lepidolita, feldspato, mica e outros, em tipos de ocorrência que vierem a ser indicados, a critério do DNPM. (BRASIL, 2008, art. $2^{\circ}$ )

Para o exercício da atividade de garimpagem, faz-se necessário a outorga do competente título minerário, expedido nos termos do Decreto-Lei n. 227, de 28 de fevereiro de 1967, e da Lei n. 7.805, de 18 de julho de 1989, sendo o referido título indispensável para a lavra e para a primeira comercialização dos minerais garimpáveis extraídos

O novo Marco de Mineração, segundo o Ministério de Minas e Energia (MME), Decreto n. 9.406/2018, publicado pelo Governo Federal em 12 de junho de 2018, atualizou o Código de Mineração, com exigências ambientais mais rígidas, como a previsão expressa da responsabilidade do minerador de recuperar áreas degradadas. O Marco prevê ainda que a Agência Nacional de Mineração (ANM) discipline, por meio de resolução, o aproveitamento de rejeitos e de resíduos da atividade mineradora, além de obrigar as mineradoras a apresentarem o Plano de Fechamento das Minas, que passou a integrar o conceito de atividade minerária. Também foi publicado o Decreto n. 9.407/2018, que trouxe novas regras para a Compensação Financeira pela Exploração de Recursos Minerais (CFEM), conhecido como royalties do setor, o qual estabelece que os municípios "não produtores", mas que sofrem impacto da atividade de mineração, recebam $15 \%$ da CFEM, pois o transporte, embarque e presença de instalações industriais no território são exemplos de impactos que dão direito a receber parte da CFEM.

Entre as propostas incluídas no novo Marco Regulatório, foram criados: o Conselho Nacional de Política Mineral e a Agência Nacional de Mineração, e também na outorga de título mineral a garantia do acompanhamento, da fiscalização e da gestão dos recursos minerais que constam no artigo 23 da Constituição Federal Brasileira. O Ministério de Minas e Energia realizou debates públicos para a reformulação do então modelo de Compensação Financeira pela Exploração de Recursos Minerais (CFEM).

\subsection{Mercado de Gemas e Joias no Brasil}

Existem cinco tendências do mercado de joias: criatividade brasileira; mercado de joias no Brasil; mercado de luxo ao redor do mundo; marketing de luxo; e inspirações para as peças. Os produtores de joias e semijoias não registraram, de maneira geral, quedas em suas produções. Os números disponíveis no relatório do McKinsey Global Institute demonstram que a expectativa de crescimento do mercado é de até $6 \%$ ao ano. As vendas do setor devem chegar aproximadamente US\$ 250 bilhões anuais até 2020 (MCKINSEY GLOBAL INSTITUTE, 2019). 
Outro ponto de destaque refere-se ao tamanho da cadeia produtiva brasileira. Uma pesquisa conduzida pelo Instituto Brasileiro de Gemas e Metais (IBGM), com 261 indústrias ligadas ao mercado de joias, apurou que o país está no ranking dos 15 maiores produtores de peças em ouro, com um total de 22 toneladas de joias criadas e comercializadas (PEREIRA; HENRIQUES, 2001). O setor de joalheria do Brasil tem destaque mundial, e seus resultados elevam o aumento da exportação de produtos nacionais para outros países, como Estados Unidos, Alemanha e Canadá, e têm um potencial crescente. Em 2018, o IBGM apurou que a exportação de pedras preciosas em estado bruto atingiu US\$ 47.590. Outras pedras preciosas lapidadas, como rubis, esmeraldas e safiras, chegaram a atingir o patamar de US\$ 83.330. As joias fabricadas com metais preciosos alcançaram US\$27.627 (IBGM, 2018).

O Brasil se destaca na produção de joias em ouro e também na produção de gemas do mundo inteiro, como ametista, citrino, água-marinha, turmalina, topázio e, em grande escala, de quartzo. Aproximadamente quatro mil empresas atuam nesse setor de joias, porém a maioria delas é de pequenos negócios. O faturamento anual do setor brasileiro de gemas já alcançou US\$ 8,2 bilhões em 2018, e esse setor tem muitas possibilidades de expansão. Uma delas é a tendência de peças com pedras naturais e com a menor lapidação possível (IBGM, 2018).

Dois fatores são importantes para o design como diferencial: o aperfeiçoamento das técnicas de produção e as tendências atuais do mercado de joias. Modelagem de joias 3D, mistura de materiais e acompanhamento dos destaques de novelas ou Fashion Weeks ao redor do mundo como um estilo ou marca, que promovem o crescimento (IBGM, 2018). Associado ao desenvolvimento do mercado de joias, a criatividade dos designs de joias traz um diferencial ao produto pelo fato de eles utilizarem pedras e materiais como couro, aço e prata. Com essa variedade para o consumidor, aumentam as chances de vendas ligadas diretamente à inovação, que muito favoreceu o mercado de joias, pois está ligada à quebra da barreira de gêneros como a produção de medalhões, gargantilhas, pulseiras, que têm sido inseridas no guarda-roupa feminino ou masculino (IBGM, 2018).

As vendas são menores nas lojas. Desde sua criação, as joias são objeto de desejo em muitos mercados. Com o intuito de ampliar essa realidade, o mercado inseriu a confecção de joias em ouro de 10 quilates em comparação ao metal de 18 quilates. Essa novidade do mercado possibilitou o acesso das pessoas a compras de joias, elevando as vendas do mercado $e$ permitindo mais investimentos em inovação e na utilização de novos materiais na composição das joias (APEX, 2018). O impacto é positivo no crescimento de joias no Brasil, porém existem muitos problemas a serem superados, como mercado atraente, que aumenta a concorrência, o que dificulta a expansão da marca do produtor isolado, e a diversificação dos fornecedores com rapidez por competitividade compromete a qualidade, diminui preços, desvaloriza o trabalho dos designers devido à produção de cópias sem autorização (APEX, 2018).

Para atender ao mercado, o Ministério da Ciência, Tecnologia e Inovação, por meio do Centro de Tecnologia Mineral (CETEM) no Rio de Janeiro, criou o Laboratório de Pesquisas Gemológicas (LAPEGE), considerado o mais moderno laboratório de pedras preciosas da América do Sul (BRASIL/LAPEGE/CETEM/MCTIC, 2014). O objetivo do Laboratório, segundo o pesquisador Jurgen Schnellrath, é melhorar o desenvolvimento do setor brasileiro de gemas, joias e bijuterias. A competência desse laboratório é identificar e caracterizar pedras e metais, com a finalidade de comprovar se uma pedra é verdadeira ou imitação e também identificar sua origem (SCHNELLRATH, 2008). No Brasil, existem diversos laboratórios de pequeno porte 
que fazem identificação básica de pedras preciosas, utilizando equipamentos de baixo custo, muitas vezes vinculados ao Instituto Brasileiro de Gemas e Metais (IBGM, 2004). Um acordo de cooperação com o Instituto Brasileiro de Gemas e Minerais representaria o setor no Brasil e no Exterior e fortaleceria as ações no setor. A certificação facilitaria as transações comerciais $e$ aumentaria a confiança do consumidor. (BRASIL/LAPEGE/CETEM/MCTIC, 2014).

\subsection{APL de Gemas e Joias}

Os Arranjos Produtivos Locais (APLs) são aglomerações de entidades especializadas em determinada região que atuam em torno de uma atividade produtiva correlata, apresentando vínculos de cooperação, de produção e de aprendizagem. Nessa região, incluem-se práticas econômicas e relações não disponíveis em outros locais.

Uma questão importante, associada a esse termo, é a formação de economias de aglomeração, ou seja, as vantagens oriundas da proximidade geográfica dos agentes, incluindo acesso a matérias-primas, equipamentos, mão de obra e outros. Considera-se que a aglomeração de empresas amplie suas chances de sobrevivência e crescimento, constituindo-se em relevante fonte geradora de vantagens competitivas. Isso é particularmente significativo no caso dos pequenos negócios. (CARDOSO; CARNEIRO; RODRIGUES, 2014, p. 7)

A iniciativa privada, em conjunto com o Governo Federal, iniciou em 1972, um esforço conjunto que culminou com a adoção de uma série de medidas voltadas para a correção dos problemas e distorções encontradas (IBGM, 2004). Em 1980, outro grupo de estudos foi criado, pois as perspectivas de comercialização externa de gemas e joias eram bastante promissoras. Esses trabalhos foram de muita importância para o setor de gemas brasileiras. Atualmente, no entanto, o Brasil ressente-se de estrutura adequada e de corpo técnico capacitado que possa atender à demanda nacional e mundial (SEBRAE, 2003).

Em agosto de 2004, foi instalado o Grupo de Trabalho Permanente para Arranjos Produtivos Locais (GTP APL) pela Portaria Interministerial n. 200, de 3 de agosto de 2004, com o apoio de uma Secretaria Técnica, lotada na estrutura organizacional do Ministério do Desenvolvimento de Indústria e Comércio Exterior (MDICE), com o objetivo de adotar uma metodologia de apoio integrado a Arranjos Produtivos Locais, com base na articulação de ações governamentais. Entre os APLs estruturados pelo Sebrae-DF, encontra-se o setor de Gemas e Joias. Ressalta-se que esse projeto foi aprovado e encontra-se em fase de estruturação (SEBRAE, 2004).

Alguns projetos estão sendo desenvolvidos como as iniciativas de inovação dos processos de lapidação das empresas integrantes, do APL de Gemas e Artefatos de Pedras de Teófilo Otoni - Fundação Centro Tecnológico de Minas Gerais (CETEC) - e o estudo das inovações e diferenciação no design de joias, lapidação e tecnologia para gemas coradas gaúchas, do APL de Gemas e Joias do Rio Grande do Sul - Fundação Vale do Taquari de Educação e Desenvolvimento Social (SEBRAE, 2004).

A formação dos lapidários ocorre na própria indústria, ou mediante experiência prática dentro da família com desconhecimento da área de gemologia. É muito incipiente a fabricação de máquinas para lapidação, principalmente por problemas de escala. Isso ocorre porque muitas indústrias fabricam ou montam suas próprias máquinas. Nesse contexto, encontra-se 
o desenvolvimento de tecnologia brasileira para a produção de uma nova máquina utilizada na lapidação de cabochão. Essa máquina produz 1,5 mil gemas por dia, todas calibradas e padronizadas. Outra máquina é a que realiza lapidação facetada, com tecnologia de Controle Numérico Computadorizado (CNC). Para identificar um mineral do ponto de vista científico, é necessário utilizar propriedades físicas e ópticas, associando itens como seu melhor aproveitamento na lapidação, considerando o ângulo específico de cada mineral e sua correta utilização na lapidação de gemas coradas e diamantes (SEBRAE, 2004).

\subsubsection{Arranjo Produtivo Local (APL) de Gemas e Joias do Distrito Federal}

Em 1996 foi criado o Museu Nacional de Gemas, sob a responsabilidade do Serviço de Apoio às Micro e Pequenas Empresas do Distrito Federal (Sebrae-DF), o acervo de gemas e joias era exposto no mezanino da Torre de TV. Entretanto, em razão da falta de incentivos fiscais, o museu foi fechado em agosto de 2010, e seu acervo foi doado para a Universidade de Brasília.

Conforme aponta o Instituto Brasileiro de Gemas e Minerais (IBGM, 2018), a Região gera muitos empregos diretos e tem um faturamento grandioso. Aproximadamente $96 \%$ da cadeia produtiva é formada de micro e pequenas empresas. Ressaltam-se as iniciativas das empresas privadas em realizar uma feira setorial, a exposição de Gemas - EXPOGEMA, e a criação da Cooperativa de Mineração dos Garimpeiros de Monte Santo (COOPERGEMAS). A Cooperativa foi criada por empresários ligados à Associação Comercial com o propósito de promover maior integração entre as empresas para dar apoio técnico e mercadológico. Os empresários associados residiam no Distrito Federal, regiões administrativas do entorno e de principais estados produtores.

Em relação ao mercado em Goiás e DF há um total de 148 empresas pesquisadas pelo Serviço de Apoio às Micro e Pequenas Empresas do Distrito Federal, 31\% consideradas informais, $51 \%$ constituem sociedades limitadas e $15 \%$ firmas individuais. Com base nessa amostra, $81,76 \%$ são microempresas e $14,19 \%$, pequenas empresas. A ourivesaria e o design $(35,8 \%)$ têm grande representatividade no Distrito Federal, seguidos pela bijuteria $(19,7 \%)$ e pelo artesanato (13,5\%). Um aspecto relevante é que quase a totalidade das empresas, 96,6\%, opera na comercialização dos produtos ou na prestação de serviços, por exemplo, no conserto de joias (MDICE, 2005).

A Coopergemas inicialmente funcionou como uma cooperativa de comercialização, embora tenha alcançado o maior nível de exportações do Distrito Federal, gerenciou durante muitos anos uma loja de comercialização de gemas e joias, localizada na Torre de TV (Tower Gem Center), juntamente com o Museu de Gemas, por meio de convênio com o Serviço de Apoio às Micro e Pequenas Empresas do Distrito Federal e, em parceria com o Instituto Brasileiro Gema e Metais Preciosos, e também um laboratório de gemas que se encontra fechado (SEBRAE, 2003). Da mesma forma, a Associação dos Joalheiros do Distrito Federal (AJODF), que reúne o comércio varejista, está desativado e sem diretoria constituída. Em 2003, foi criada a Associação Brasileira dos Pequenos e Médios Produtores de Gemas, Joias e Similares; Mineradores e Garimpeiros (ABRAGEM) que congrega empresas de vários estados brasileiros.

Em 14 de maio de 2007, houve a assinatura do Termo de Cooperação Técnica, como a atuação do Sebrae-DF, no sentido de viabilizar a realização de ações visando a implantar o 
Núcleo de Apoio aos Arranjos Produtivos Locais do Distrito Federal. O APL de Gemas e Joias foi incluído nos APLs do Setor de Comércio e Serviços (SEBRAE-DF, 2004).

O Plano de Desenvolvimento do Arranjo Produtivo de Gemas e Joias do Distrito Federal tem importância para orientar a integração e a convergência de ações dos agentes que atuam neste cenário, colaborando para formalizar novas parcerias com o objetivo de otimizar recursos, envidar esforços, fortalecer de escopos comuns e consolidar o processo de cooperação e de interação dos atores. As ações desse Plano de Desenvolvimento foram elaboradas e validadas pelos atores da Governança do Arranjo Produtivo Local cujo objetivo principal foi aumentar a competitividade e a cooperação das empresas fabricantes e comerciais de Gemas e Joias, focado na melhoria do processo produtivo, no aumento de participação do setor no mercado interno e na conquista do mercado externo (SEBRAE-DF, 2004).

A elaboração do Plano de Desenvolvimento Preliminar (VIANA, 2007) teve como referência o Manual Operacional (Modelo de Plano de Desenvolvimento), disponibilizado pelo Ministério do Desenvolvimento, Indústria e Comércio Exterior, e informações de diversas instituições (SEBRAE-DF, 2004; SEBRAE, 2003). O Arranjo Produtivo de Gemas e Joias do DF é formado por micros e pequenas empresas do Distrito Federal e Entorno. A caracterização dos modelos de Arranjos Produtivos Locais prevê a existência de uma concentração geográfica de empresas, fornecedores, prestadores de serviços, entidades associadas, competitivas e cooperadas entre si. Os Arranjos Produtivos Locais precisam de apoio institucional para assegurar a promoção da sua competitividade e sustentabilidade (SEBRAE-DF, 2004).

A partir de 2010, foi instituído o Comitê Temático de APLs de Base Mineral (CT APL Mineral) em Goiânia-GO, com o apoio de SETEC/MCTIC, SGM/MME, IBICT, CETEM e GTP APL/MDIC. Por motivos de baixa adesão e participação das instituições dos diversos segmentos minerais que atuam com a estratégia de desenvolvimento dos Arranjos Produtivos Locais de base mineral, esse CT só funcionou até o final do ano de 2013. No período de 2013 a 2018, houve a participação adicional dos seguintes parceiros: Superintendência do Desenvolvimento do Centro-Oeste (SUDECO) e do Banco do Nordeste do Brasil (BNB) e apoio da Secretaria de Desenvolvimento Regional da Secretaria de Desenvolvimento Regional do Ministério da Integração Nacional (SDR/MI) (APEX, 2018).

No mês de setembro de 2017, a designer brasiliense de joias, Carla Amorim, foi convidada para fazer parte da One Jewelry, loja multimarcas inaugurada naquele ano em Xangai, na China, que visa a promover as últimas tendências internacionais em joalheria. Única empresa brasileira do portfólio, Carla Amorim faz parte do projeto setorial Precious Brazil, desenvolvido pelo Instituto Brasileiro de Gemas e Metais Preciosos (IBGM) com a Agência Brasileira de Promoção de Exportações e Investimentos (APEX-Brasil), e, ao longo dos últimos dez anos, vem sendo apoiada em inúmeras feiras internacionais que permitiram a internacionalização da marca.

O Projeto Setorial Precious Brazil visa a apoiar e a promover as empresas brasileiras dos segmentos de pedras, bijuterias e joias brasileiras que queiram exportar seus produtos, sejam elas iniciantes, exportadoras ou internacionalizadas. Conduzido pelo IBGM, em parceria com a Apex-Brasil, o projeto atende atualmente cerca de 181 empresas do setor. O projeto é gerido por um Comitê Gestor composto de representantes de segmentos diversos, tendo capilaridade em 11 estados brasileiros, e atua nos mercados dos Estados Unidos, China, Hong Kong, Alemanha, Chile e Colômbia (APEX, 2018). 
Em 2 de fevereiro de 2018, conforme solicitação realizada pelas recomendações aprovadas pela Plenária do CT Rede APL mineral nos eventos do X a XIV Seminário Nacional de APLs de Base Mineral e VIII a XI Encontro do CT Rede APL mineral, realizados de 2014 a 2017, foi instituído o Comitê Temático Rede Brasileira de Arranjos Produtivos Locais de Base Mineral - CT Rede APL mineral (APLs de Base Mineral) sob a coordenação do MCTIC/SETEC e apoio do GTP APL/MDIC. O CT Rede APL mineral constitui-se numa instância cooperativa de coordenação e integração de ações dos APLs de Base Mineral e de informações de abrangência nacional.

Com base nas informações do portal da rede, seus objetivos são: planejar a longo prazo, estruturar, integrar, coordenar, acompanhar e avaliar as ações das instituições que atuam na promoção dos APLs de Base Mineral e que contribuem para a formulação de políticas públicas para o desenvolvimento sustentável dos APLs de Base Mineral do país, no âmbito do GTP APL; promover a sistematização, disponibilização e disseminação de informações e das diversas formas de conhecimento vinculadas às cadeias produtivas de segmentos minerais priorizados e organizadas em APLs de Base Mineral; difundir e popularizar as boas práticas em APLs de Base Mineral; fornecer informação para subsidiar a elaboração de políticas públicas para o desenvolvimento dos APLs de Base Mineral; e manter o sistema de gestão da informação dos APLs de Base Mineral.

Quadro 1 - Linha do tempo APL Gemas e Joias do DF

\begin{tabular}{|c|c|}
\hline 1996 & Museu de Gemas e Joias é inaugurado na Torre de TV de Brasília, DF. \\
\hline 2004 & $\begin{array}{l}\text { Constituição da Rede Brasileira de Informação de Arranjos } \\
\text { Produtivos Locais de Base Mineral - Rede APL mineral. }\end{array}$ \\
\hline 2007 & $\begin{array}{c}\text { Participação do Centro de Tecnologia Mineral (CETEM), do Instituto Brasileiro } \\
\text { de Informação em Ciência e Tecnologia (IBICT) e da Associação Brasileiras } \\
\text { das Instituições de Pesquisa Tecnológicas e Inovações (ABIPTI). }\end{array}$ \\
\hline 2007 & $\begin{array}{c}\text { Assinatura do Termo de Cooperação Técnica - Atuação } \\
\text { do Sebrae-DF em Arranjos Produtivos Locais. }\end{array}$ \\
\hline 2010 & Instituído o Comitê Temático de APLs de Base Mineral - CT APL Mineral em Goiânia, GO. \\
\hline 2010 & $\begin{array}{l}\text { Desativação do Museu de Gemas e Joias na Torre de TV e } \\
\text { doação do espaço para a Universidade de Brasília. }\end{array}$ \\
\hline 2013-2018 & $\begin{array}{l}\text { Participação adicional dos parceiros: Superintendência do Desenvolvimento } \\
\text { do Centro-Oeste (SUDECO), do Banco do Nordeste do Brasil (BNB), } \\
\text { e o apoio da Secretaria de Desenvolvimento Regional da Secretaria de } \\
\text { Desenvolvimento Regional do Ministério da Integração Nacional (SDR/MI). }\end{array}$ \\
\hline 2017 & $\begin{array}{l}\text { A designer de joias brasiliense, Carla Amorim, foi convidada a fazer parte } \\
\text { da "One Jewelry", loja multimarcas inaugurada em Xangai, na China, que } \\
\text { visa a promover as últimas tendências internacionais em joalheria. }\end{array}$ \\
\hline 2018 & $\begin{array}{l}\text { Foi instituído o Comitê Temático Rede Brasileira de Arranjos Produtivos } \\
\text { Locais de Base Mineral - CT Rede APL mineral (APLs de Base Mineral) } \\
\text { com a coordenação do MCTIC/SETEC e apoio do GTP APL/MDIC. }\end{array}$ \\
\hline
\end{tabular}

Fonte: Elaborado pelos autores deste artigo 


\subsubsection{Arranjo Produtivo Local (APL) de Gemas, Joias e Artesanato Mineral de Cristalina (GO)}

Em Goiás há uma grande produção de gemas, com destaque para ametista, berilo, citrino, esmeralda, granada, topázio, quartzo e turmalina, com reservas espalhadas em diversas regiões (MDICE, 2005, p. 52).

Cristalina é um município do estado de Goiás e faz parte da Região Metropolitana do DF (Figura 1). Durante anos, a economia da região se baseou na exploração de cristais que eram exportados para a Europa para confecção de joias. Na década de 2010, a atividade produtiva em Cristalina passou por um período de recuperação, com o apoio financeiro concedido pelo Fundo Mineral do Estado, cujos financiamentos têm prazo de 48 meses, com seis meses de carência e juros de 6\% ao ano. Os mais de 120 empresários e artesãos da região - metade deles está associada à Associação dos Produtores de Pedra de Cristalina (ASPEC) - direcionaram suas linhas para produtos utilitários, como artefatos minerais, tabuleiros de xadrez, bandejas, etc.

Figura 1 - Arranjo Produtivo Local de Gemas, Joias e Artesanato Mineral de Cristalina
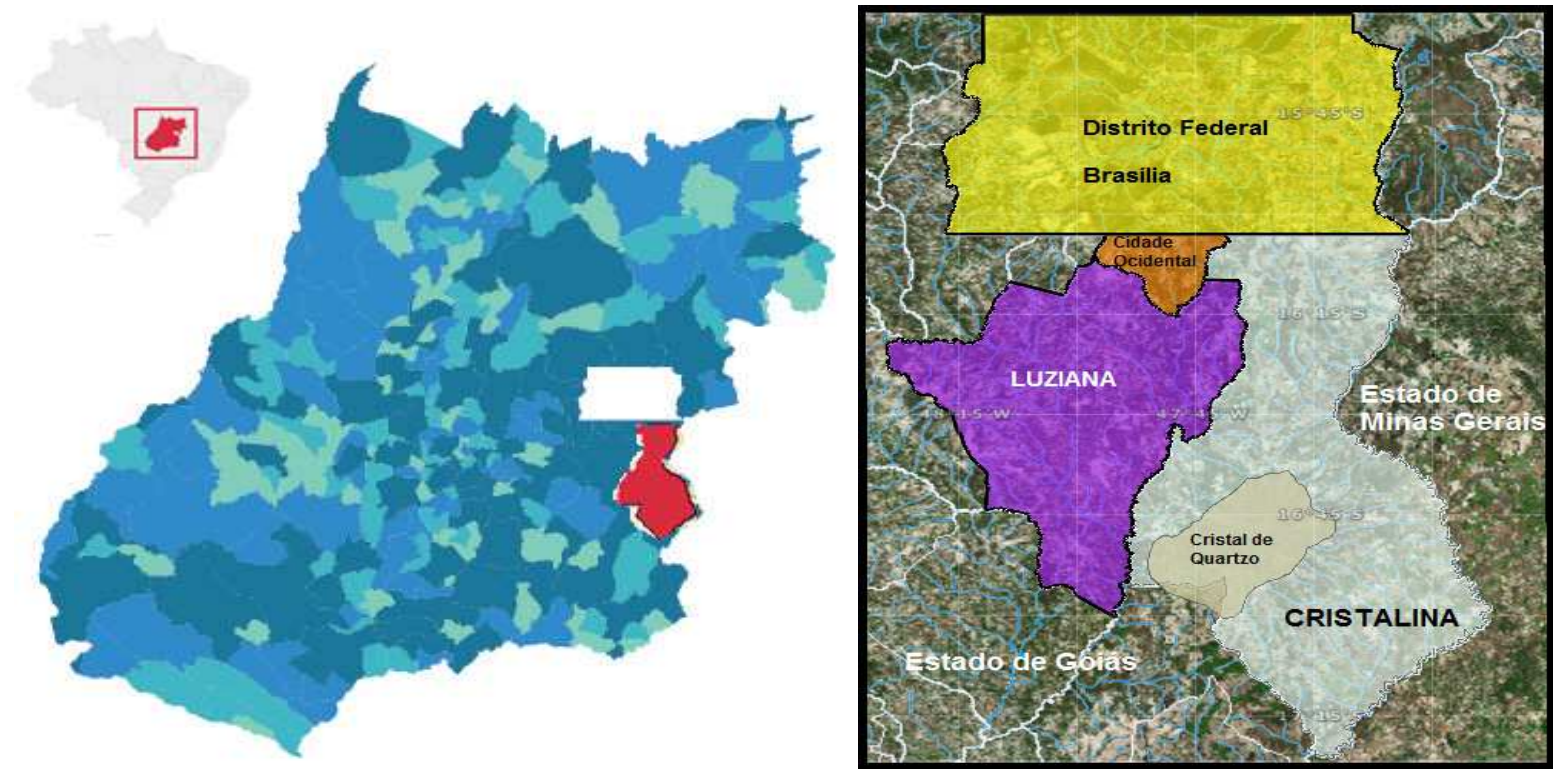

Fonte: Cristalina (2018)

Nesse cenário, o setor de gemas, joias e folheados do estado de Goiás, apesar da baixa qualificação da mão de obra, desatualização dos equipamentos e reduzida atuação coletiva, mas dada a potencialidade das suas reservas minerais, a existência de um bom número de empresas/artesões e o interesse do governo e de outros órgãos de fomento, fez com que surgisse as pré-condições que habilitam a estruturação de um polo em associação às atividades turísticas, pois o estado possui produtos turísticos extremamente interessantes (místico, ecoturismo, aventura, rural, estâncias minerais e cultural), além de festas tradicionais, como a Procissão do Fogaréu, Congadas, Folia de Reis e a Festa do Divino, entre outras (MDICE, 2005, p. 53). Em 2019, Pirenópolis, GO, recebeu uma IP para artesanato de joias.

Porém, algumas lideranças locais evidenciaram que um trabalho de valorização da habilidade individual dos artesãos, associado ao aproveitamento de matérias-primas locais e regionais, valorizando a técnica, a criatividade e a melhoria do design das peças encontraria grande receptividade. No entanto, houve necessidade de se realizar, entre outros, um trabalho consistente 
de melhorias de processos produtivos e incorporação de design que permitisse diferenciar o produto e associá-lo a uma localidade ou aspecto regional, além de promoção comercial, para dar visibilidade (MDICE, 2005, p. 54).

Até a joia chegar ao cliente, existem várias etapas na cadeia de mineração, como a lapidação, o pedido de se fazer a joia e a comercialização pela joalheria. No âmbito do DF, predomina o contato do cliente com a joalheria. Na Região Metropolitana do DF, em Cristalina (GO), há a lapidação, o trabalho artesanal e a forma de esculpir a pedra. Os dois APLs são focados em dois eixos diferentes da cadeia produtiva. A comercialização conjunta acontece no DF onde há o maior mercado. Entretanto, todos os processos de produção e de comercialização são diferenciados, o que indica alguma sinergia (por exemplo, lapidação e produção), mas em geral objetivos de mercado diferentes, o que dificulta a realização de um plano de mercado comum.

\subsubsection{Discussão}

De acordo com uma análise SWOT, podem ser identificados pontos fortes e fracos dos APLs analisados. Os pontos fortes do Setor de Gemas, Joias e Bijuterias foram assinalados: mercado local favorável e com grande poder aquisitivo; proximidade de regióes onde se encontram a matéria-prima e os fornecedores; perspectivas favoráveis para o setor, em função do seu crescimento em nível nacional; e qualidade dos produtos e serviços, em especial o design.

Destaca-se que, para os pontos fracos, registrou-se: alto índice de informalidade; dificuldade de acesso ao crédito; insegurança quanto a roubos e furtos; baixa integração entre as empresas do setor; ausência de políticas públicas de estímulo ao setor; deficiências na gestão empresarial e no emprego de mão de obra pouco qualificada; necessidade de fortalecer parcerias entre as empresas para aquisição de matéria-prima; falta de qualificação de pessoal, de formação gerencial e de criação de empresas de gemas lapidadas, de joias e de embalagens. Enfim, também é importante criar a integração com o setor de turismo, além da realização de promoção comercial, com a participação das empresas brasilienses em feiras nacionais e internacionais. Destaca-se que sobre os APLs do DF, o ponto forte é a proximidade do mercado e a disponibilidade de mão de obra especializada. O APL de Cristalina tem como ponto forte a proximidade da mineração e o mercado turístico.

Os dois APLs têm como ponto fraco os planos de desenvolvimento e de gestão. Uma das grandes ameaças é alta tributação; a elevada informalidade; a concorrência realizada por empresas de outros estados, como São Paulo e Minas Gerais, além dos produtos importados dos países orientais e a falta de tradição do setor no Distrito Federal. A grande oportunidade é que não existe concorrência nacional e internacional e o mercado, que é em expansão e ainda de grande porte, sem necessidade de trabalhar os nichos e ter grandes gastos em termos de custos para diferenciação dos segmentos.

Em relação aos produtos, os metais mais utilizados são o ouro e a prata, seguidos do paládio e do cobre na composição das ligas. A maior parte da matéria-prima, como o ouro utilizado na confecção das joias, é adquirida por meio dos leilões da Caixa Econômica Federal na cidade de Brasília. Enquanto as gemas em estado bruto e lapidadas são supridas por fornecedores de Cristalina (GO), Anápolis (GO), Teófilo Otoni (MG), Belo Horizonte (MG), São Paulo (SP), Rondônia e Paraíba, entre outros. Tendo em vista o preço elevado das matérias-primas, $42 \%$ das empresas adquirem o indispensável para a produção imediata. Cerca de $20 \%$ delas mantêm estoque para até 30 dias. 
Um problema é a gestão dos ativos e máquinas, pois, conforme aponta a pesquisa realizada, $35 \%$ das empresas não efetuam nenhum tipo de manutenção nos equipamentos, e a grande maioria das empresas (76\%) não desenvolve um programa de proteção ambiental, nem de controle de gases tóxicos no processo de purificação de gases tóxicos no processo de purificação de metais, ourivesaria e fundição.

Com relação ao mercado internacional, somente 6,7\% das empresas exportam seus produtos, sendo que $60 \%$ das vendas são realizadas diretamente para o consumidor e para o comércio varejista. A maioria das empresas divulga seus produtos via folhetos, rádio/televisão, revistas e jornais. A propaganda "boca a boca" se apresenta como a segunda maior forma de divulgação. As feiras e exposições têm sido muito pouco utilizadas pelas empresas do Distrito Federal como instrumentos de promoção de divulgação dos seus produtos (MDICE, 2005).

\title{
4 Considerações Finais
}

A pesquisa teve como base uma análise bibliográfica e desenvolveu também uma coleta de dados que se deu por meio de entrevistas, observação não participante e análise documental. A pesquisa de campo mostrou que a disponibilidade das informações por parte das empresas produtoras de joias é bem restrita, entretanto, mostrou também a oportunidade e o potencial de criação de um Arranjo Produtivo Local de Gemas e Joias e Artesanato na Região Metropolitana do DF em Cristalina (GO). No decorrer da pesquisa, bibliográfica e qualitativa, foi detectado que no DF existia inicialmente um APL de gemas e joias que foi desativado, permanecendo APL de Gemas e Joias na Região Metropolitana do DF em Cristalina (GO).

Verificou-se então que existem muitos problemas a serem superados para desenvolver um projeto de marca, seja IG ou marca coletiva, ligado à cadeia produtiva, principalmente a falta da cultura de cooperativismo e de associativismo. Além disso, há limitações, como a diversificação dos fornecedores, pela rapidez de produção, e a competitividade que compromete a qualidade dos produtos. Observou-se que a confecção das joias ainda é bem artesanal, indicando uma escassez de mão de obra qualificada e que a maioria dos negócios do ramo envolve empresas familiares. Evidenciou-se também a falta de incentivos fiscais para o crescimento do setor na Região. Por esses problemas, antes de predispor pedidos de IG e marcas coletivas, a sugestão é de que é necessário melhores planejamento e análise de marketing de todas as atividades.

\section{Referências}

\begin{abstract}
ABRAGEM - ASSOCIAÇÃO BRASILEIRA DOS PEQUENOS E MÉDIOS PRODUTORES DE GEMAS, JOIAS E SIMILARES; MINERADORES E GARIMPEIROS Estatudo. Abragem, 2010. Disponível em: www.abragem.org. Acesso em: 15 fev. 2021.
\end{abstract}

ANM - AGÊNCIA NACIONAL DE MINERAÇÃO. Brasília, DF: outubro de 2018. Disponível em: http://www.anm.gov.br/dnpm/publicacoes. Acesso em: 3 nov. 2018.

APEX - AGÊNCIA DE PRODUÇÃO PARA O COMÉRCIO EXTERIOR. Brasília, DF, 2018. Disponível em: http://www.apexbrasil.com.br/Noticia. Acesso em: 30 out. 2018. 
BOXER, Charles R. Idade de Ouro do Brasil: dores de crescimento de uma sociedade colonial. Rio de Janeiro, RJ: Nova Fronteira, 1969.

BRASIL MCT/SETEC/CGTS. Desenvolvimento e inovação tecnológicas. In: IV SEMINÁRIO NACIONAL DE APL DE BASE MINERAL, Curitiba-PR, 19- 21 set. 2007. Anais [...]. Curitiba, PR, 2007.

BRASIL. Lei n. 11.685, de 2 de junho de 2008. Institui o Estatuto do Garimpeiro e dá outras providências. Brasília, DF: Senado Federal, 2008.

BRASIL/LAPEGE/CETEM/MCTIC. Rio de Janeiro, 2014. Disponível em: http://www.cetem.gov.br/ lapege. Acesso em: 30 out. 2018.

CARDOSO, Univaldo Coelho; CARNEIRO, Vânia Lúcia Nogueira; RODRIGUES, Édna Rabêlo Quirino. APL: Arranjo Produtivo Local. Brasília, DF: Sebrae, 2014.

CRISTALINA. Goiás, GO. Histórico. [2018]. Disponível em: https://biblioteca.ibge.gov.br/ visualizacao/dtbs/goias/cristalina.pdf. Acesso em: 15 de outubro de 2018.

IBGM - INSTITUTO BRASILEIRO DE GEMAS E MATERIAIS PRECIOSOS. Manual Técnico de Gemas. Brasília, DF: IBGM, 2001. 124 p.: il.

IBGM - INSTITUTO BRASILEIRO DE GEMAS E MATERIAIS PRECIOSOS. Manual Técnico de Gemas. Brasília, DF: IBGM, 2005. 50 p.

IBGM - INSTITUTO BRASILEIRO DE GEMAS E MATERIAIS PRECIOSOS. Mineração e Desenvolvimento Sustentável. Brasília, DF: Departamento Nacional de Produção Mineral, 2004.

IBGM - INSTITUTO BRASILEIRO DE GEMAS E MATERIAIS PRECIOSOS. Núcleo de Inteligência Competitiva (NIC) para a Cadeia Produtiva de Gemas, Joias e Afins, projeto do IBGM: Setor em Grandes Números 2018. Disponível em https://ibgm.com.br/ibgm-informa/ publicacoes/. Acesso em: 26 fev. 2021.

LAKATOS, E. M.; MARCONI, M. A. Fundamentos da Metodologia Científica. 5. ed. São Paulo: Atlas, 2003. 315p.

MCKINSEY GLOBAL INSTITUTE. The state of fashion 2019. McKinsey global Institute. 2019. disponivel em www.mckinsey.com/ /media/mckinsey/industries/retail/ acesso o dia $15 \mathrm{de}$ fevererio de 2021.

MI - MINISTÉRIO DA INTEGRAÇÃO. Arranjos Produtivos Locais nos Espaços Prioritários dos Programas de Desenvolvimento Regional, PPA 2004- 2007. Brasília, DF, 2008.

MDICE - MINISTÉRIO DO DESENVOLVIMENTO, INDÚSTRIA E COMÉRCIO EXTERIOR.

Políticas e Ações para a Cadeia Produtiva de Gemas e Joias/Ministério do Desenvolvimento, Indústria e Comércio Exterior. Coordenação de Hécliton Santini Henriques, Marcelo Monteiro Soares. Brasília, DF: Brisa, 2005. 116 p.: il.

MNE - MINISTÉRIO DE MINAS E ENERGIA. Proposta da $4^{\text {a }}$ Fase do Programa Setorial Integrado de Apoio às Exportações de Gemas, Joias e Afins. Brasília: IBGM, 2004.

OLIVEIRA, Maurício Lopes de. Direito de Marcas. Rio de Janeiro: Lumen Juris, 2004. 
PEREIRA, Roberto Costa; HENRIQUES, Hécliton Santini. Ouro, Gemas e Jóias: em busca de um entendimento. Brasília, DF: IBGM, MNE, 2001.

SALLES, FRITZ TEIXEIRA DE. Associações religiosas no Ciclo do Ouro. Rio de Janeiro, RJ. Perspectiva, 1963.

SCHNELLRATH, J. Opalas azuis: umas falsas, outras verdadeiras. In: CONGRESSO BRASILEIRO DE GEOLOGIA, 44, Curitiba, 2008. Anais [...]. Curitiba, PR, 2088.

SEBRAE - SERVIÇO BRASILEIRO DE APOIO ÀS MICRO E PEQUENAS EMPRESAS. Termo de Referência para Atuação do Sistema Sebrae em Arranjos Produtivos Locais. Brasília: SEBRAE, 2003.

SEBRAE-DF - SERVIÇO BRASILEIRO DE APOIO ÀS MICRO E PEQUENAS EMPRESAS DO DISTRITO FEDERAL. Estudo de Mercado dos Setores de Gemas, Joias, Bijuterias e Correlatos, setembro 2004.

SZMRECSÁNYI, TAMÁS. História econômica do Período Colonial. São Paulo, SP: Hucitec; Edusp, 2008.

VALE, EDUARDO. O que é economia mineral. [2018]. Disponível em: http://www.geologo.com. br/economiamineral.asp. Acesso em: 10 out. 2018.

VIANA LEITE ROGERIO. Plano de Desenvolvimento do Arranjo Produtivo de Gemas e Jóias do Distrito Federal. Ed. SEBRAE 2007.

\title{
Sobre os Autores
}

\author{
Alessandro Aveni \\ E-mail: alessandro@unb.br \\ Doutor em Administração. \\ Endereço profissional: Universidade de Brasília, Mestrado PROFNIT, Brasília, DF. CEP: 70910-900.
}

\section{Ângelo Magalhães Júnior}

E-mail: angelomagalhaes1@gmail.com

Bacharel em Direito.

Endereço profissional: Embrapa Empresa Brasileira de Pesquisa Agropecuária, Col. Agrícola Sucupira, s/n, Riacho Fundo I, Brasília, DF. CEP: 71707-970.

\section{Claudina Maria Costa}

E-mail: claudina6costa@yahoo.com.br

Graduada em Administração.

Endereço Profissional: Ministério da Economia Comércio Exterior e Serviços, Esplanada dos Ministério, bloco J, Brasília, DF. CEP: 71707-970.

\section{Lúcia de Assunção}

E-mail: luciaint17@gmail.com

Graduada em Psicologia.

Endereço profissional: Universidade de Brasília, Mestrado PROFNIT, Brasília, DF. CEP: 70910-900. 